\title{
CREATION OF IMAGE MODELS FOR EVOLVING OBJECTS ON DYNAMICALLY CHANGING SCENES
}

\author{
Yury Ipatov $^{1^{*}}$ Alexandr Krevetsky ${ }^{1}$ Yury Andrianov ${ }^{1}$ Boris Sokolov $^{2}$ \\ ${ }^{1}$ Volga State University of Technology, Russia \\ ${ }^{2}$ Saint Petersburg Institute of Informatics and Automation, Russian Academy of Sciences (SPIIRAS), \\ Russia, Saint Petersburg
}

An overview of the theoretical approaches to the formation of models images by key features. Dynamically changing scene images with selected objects of interest and background is reviewed. The statistical characteristics of this class of images are explored. Model convex hulls sampling distributions background / object in different colorimetric spaces were obtained. Synthesized model ellipsoids based on them using optimization methods give a good score for approximate calculation. Identified areas for further research and the use of the current results. Estimates of segmentation quality for algorithms based on synthesized models are calculated.

Key words: Approximation of the ellipsoid, Model of the convex hull, Nonuniform background, Colorimetric space, Dynamically changing scene, Segmentation algorithm

\section{INTRODUCTION}

Construction of mathematical models based on the image characteristic features finds widespread practical application in vision systems for image analysis and pattern recognition. Search images based on descriptions [01], the navigation of autonomous unmanned vehicles in space [02], biometric authentication [03], that some modern and high-tech science and technology, where these approaches are implemented. The existence and operation of intelligent systems would not be possible without the creation of adequate models of digital images.

Analysis of existing approaches to describe the images shows that there are so-called low-level description of the model, which is based on basic values: the color, brightness, singular points, angle [04]. Allocation of these features is not accompanied by a reference to the information about the shape of the object or the interposition of its individual parts. At the same time, to build higher-level features [05] it is necessary. Sometimes high-level view uses some derivative forms. Additional features characteristic descriptor of the representation mode can be called a contour, texture, structure, fractal and etc.

A variety of approaches to the formation of models by digital images does not solve the problem, creating a universal and unified theory methods in these studies. Creation and development of such models is highly dependent on the context of the problem being solved and the image of this class. Therefore, the synthesis of adequate mathematical models seems urgent research priority.

The aim is to develop theoretical models of selective distribution image dynamically changing scenes of plant growth. To achieve the goal of research is needed to solve the problems of the analysis the statistical characteristics by images class, as well as the synthesis of mathematical models based on convex hulls and curves of the second order.

\section{IMAGE SEGMENTATION ALGORITHM}

To create an efficient and high-performance algorithm for image segmentation with dynamically changing scenes, the core of created algorithm have to use consistent data for decision-making. For example, the created software package can be used for images of the following class, shown in Figure 1.
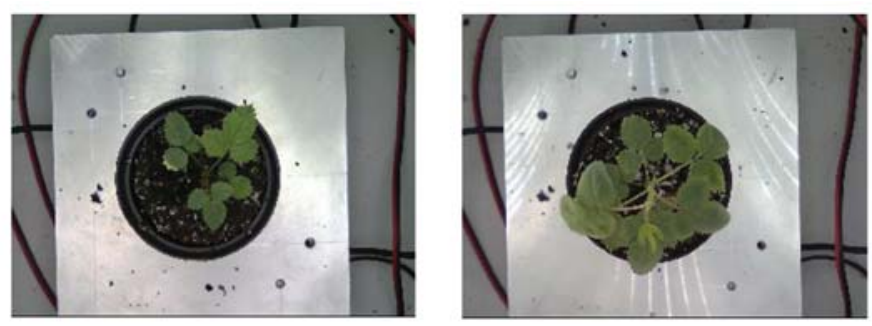

Figure 1: Example of dynamically changing scenes

However, the choice of the best model for describing the "background / object" distribution requires detailed research, as well as assessments of the functioning quality for software solutions on their basis. Here is the general block diagram of the segmentation algorithm for the general case Figure 2.

On the basis of the obtained models, segmentation algorithms for different colorimetric spaces will be created. With the help of expert assessments, it will be necessary to find out which model will give the best characteristics for the "background / object" separation. 


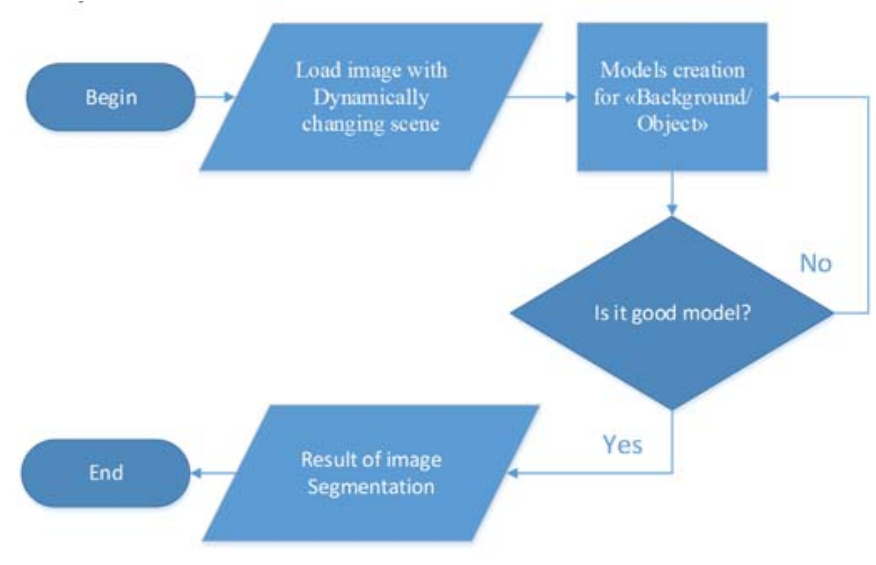

Figure 2: Block diagram of the software for image segmentation system

\section{STATISTICAL CHARACTERISTICS}

Modern photorecording equipment used for fixing dynamically changing scenes of vegetation, has a high resolution of luminance and chromatic components. When registering this class there are different kinds of image noise [06], which can be approximated by an independent centered normal noise for each color component. In addition, for locally uniform areas of the image by the color evaluation apparatus optimal luminance or color channels in this type of noise is a spatial moving average filter [07]. To analyze and research are taken image, and also by colorimetric models that were previously obtained [08].

When creating a dynamic segmentation algorithm, it is necessary to know the statistical characteristics of the random distribution land areas and background objects (plants). From the brightness histogram for the scenes to be that they do not have distinct modes corresponding statistical inhomogeneous background and projective cover of plants, so the direct use of the known methods of histogram segmentation threshold for global challenges division into classes of objects is not possible. The analysis of the histogram in Figure 3 for these types of images confirm this conclusion. Background luminance has considerable statistical scatter of values, as well as the spatial heterogeneity of the statistical characteristics. Therefore the brightness is not an essential feature for the selective class of objects investigated dynamically changing scenes.

Basic statistical characteristics of the background on the dynamically changing scenes are shown in Table 1 . The sample size is $0,75^{*} 10^{6}$ points.

An analysis of the statistical data for the observed image leads to the following conclusions. The average brightness of the background objects ranges from 0 to 255 , and the value is $\sigma=33,5$ not contrary to the rule of $3 \sigma$. Objects of study plants have a pronounced elliptical shape, and border transition "sheet / background" stand high contrast. Statistical nonuniform background does not have a distinct shape and can not be considered as a closed object, the color tone is typical for large statistical variations in the brightness. Some background objects has a hue similar to the object under study.

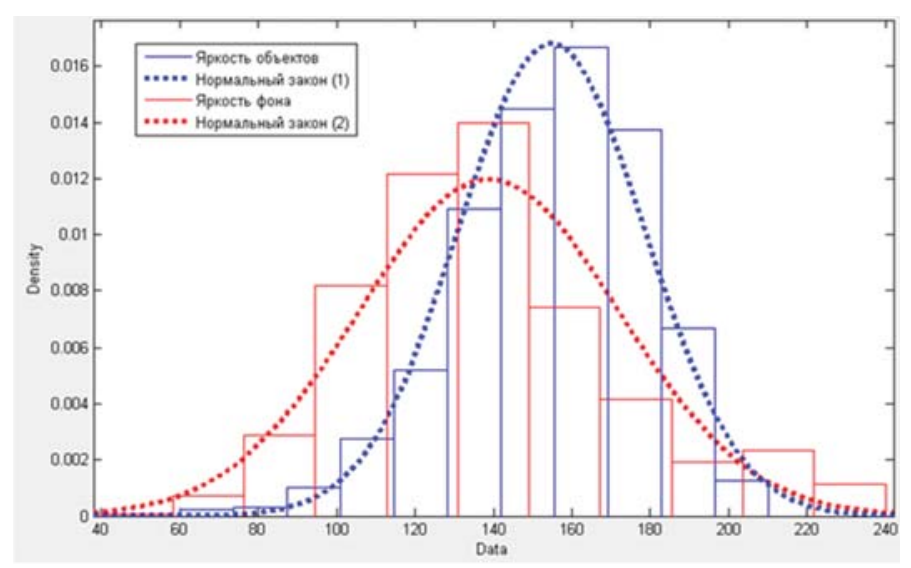

Figure 3: Theoretical and empirical evidence of selective brightness background / object

\begin{tabular}{|c|c|c|c|}
\hline $\begin{array}{c}\text { Avg. value } \\
\text { brightness }\end{array}$ & $\begin{array}{c}\text { Median } \\
\text { brightness }\end{array}$ & $\begin{array}{c}\text { Mode } \\
\text { brightness }\end{array}$ & $\begin{array}{c}\text { Min } \\
\text { brightness }\end{array}$ \\
\hline 138 & 135 & 94 & 0 \\
\hline $\begin{array}{c}\text { Max } \\
\text { brightness }\end{array}$ & Dispersion & $\begin{array}{c}\text { Asymmetry } \\
\text { coefficient }\end{array}$ & $\begin{array}{c}\text { Kurtosis } \\
\text { coefficient }\end{array}$ \\
\hline 255 & 1120 & $-0,23$ & $-0,39$ \\
\hline
\end{tabular}

Table 1: Statistical characteristics

The computational efficiency on the scanned data set and a large amount of sample values, justify, to test the normality for the statistical distribution of the luminance background component using Kolmogorov-Smirnov test. The value of the criterion $\lambda$ is calculated using the formula:

$$
\lambda=\sqrt{n}\left(\max _{\forall x}\left|F_{x}(x)-\widetilde{F}_{x}(x)\right|\right)
$$

where $\widetilde{F}_{x}(x)$ - sample empirical distribution function, $F_{x}(x)$ - theoretical sampling distribution function and $n$ - sample size. For the confidence level $\alpha=0,01$ of the value quintile distribution $\lambda_{\alpha}=1,628$ (table value) and the value of statistics, calculated by the formula (1) $\lambda=4,389$ is (at $n=0,75 \cdot 10^{6}$ points).

Therefore, since $\lambda_{\alpha}>\lambda$ the hypothesis of normal distribution of background image we reject this class.

The asymmetry coefficient Pearson

$$
A s=\left[\sum_{i=1}^{m}\left(x_{i}-\bar{x}\right)^{3} * n_{i}\right] \cdot\left(\sigma^{3} \sum_{i=1}^{m} n_{i}\right)^{-1}=-0.23
$$

where $m$-group number, $\bar{x}$ - average value and $n_{i}-$ rate shows slight left-sided asymmetry. 
A measure of excess

$$
E x=\left[\sum_{i=1}^{m}\left(x_{i}-\bar{x}\right)^{4} * n_{i}\right] \cdot\left(\sigma^{4} \sum_{i=1}^{m} n_{i}\right)^{-1}-3=-0.39
$$

It indicates a small plateau distribution.

In general it can be concluded that the level of non-uniform background brightness and has a characteristic, well-defined structure.

\section{MODEL CONVEX POLYHEDRON}

Object describing the space-point model and fields, a well-researched and discussed in scientific papers $[09,10]$. In a wide class of practical aspects for vision systems, there are approaches based on the view point of the scene in the form of graphs, for example, the minimum spanning tree [11] for the problem of groups point objects recognition. There are also a quaternion model [12], wire model [13], solid associated image [14] and others. All these models are used in the specific recognition tasks where you need to take into account the features of the scene description, and take into consideration the context problem being solved.

Building models of selective distribution in their description of a point to imply that the objects described by the set of points where each point has a vector representation. Depending on the choice of colorimetric model, the value of the vector quantity change.

The problem of constructing a minimum convex hull is a fundamental task of computational geometry, with a broad profile of practical application in pattern recognition and image analysis. The calculation of the minimum convex hull on a finite set of points in two-dimensional and three-dimensional case, well studied and investigated in detail [15]. Under the minimum convex hull will understand this is such a shell, which is the smallest convex polygon perimeter in the two-dimensional case, and a minimum size of external faces of the three-dimensional case.

Today there are, many methods to build a minimum convex hull: Graham, Jarvis, Chen et al. So if the dimension $n$ - defines a set of points, and the value $h$ - the number of vertices of the convex hull, the computational complexity of the alqorithms have to be Graham - $\Theta(n \cdot \log n)$-Jarvis $\Theta\left(n^{2}\right)$ and Chen $-\Theta(n \cdot \log h)$. It should be noted that the algorithm is unique Chen synthesis algorithms Jarvis and Graham, allowing give better computational performance.

To construct a minimum convex hull of a point for their representation in the colorimetric spaces were experimentally selected four the most diverse forms of selected laws distribution. Among these color spaces: RGB, $\mathrm{Lab}, \mathrm{HSV}, \mathrm{YCrCb}$. Figure 4 shows the result of the construction of the minimum convex hull for the class of dynamically changing scene images in $\mathrm{YCrCb}$ color space. Visualization of the results shows the most characteristic features of selective distribution in these color spaces.
So the area of overlap joint spatial clusters of complex spatial form, which requires the establishment in each case, their approach to the division of the observed sets.

\section{ELLIPSOID MODEL}

Creation of models based on the convex hull, requires the solution of problems belonging to the set, to solve a computationally intensive task. Therefore, it is advisable to reduce the dimension of the object described by approximation, any geometric primitives, which has an analytic representation. So in this respect there are fundamental works, allowing a plurality of convex polyhedra approximate [16] and methods of polyhedral approximation [17].

The best in terms of analytic representation and computational complexity will consider the curves of the second order approximation problem for the considered set. The surface of the second order is called a geometric shape that can be described by the equation in Cartesian coordinates:

$$
\begin{gathered}
A \cdot x^{2}+B \cdot y^{2}+C \cdot z^{2}+2 \cdot D \cdot x \cdot y+2 \cdot E \cdot x \cdot z+ \\
2 \cdot F \cdot y \cdot z+G \cdot x+H \cdot y+I \cdot z+J=0
\end{gathered}
$$

Equation (4) provides a six types of the second kind surfaces, however, the study sample sets [08] give reason to consider the problem of constructing models sphere and ellipsoid. Since the sphere is a special case of an ellipsoid, for the practical task of creating the optimal model will be considered - ellipsoid. Canonical equations given this figure is determined by:

$$
\frac{x^{2}}{a^{2}}+\frac{y^{2}}{b^{2}}+\frac{z^{2}}{c^{2}}=1
$$

Review of existing approaches $[18,19]$ shows that the creation of the "best" in terms of the approach to a given set of points there: the ellipsoid of minimal volume, ellipsoid principal component, ellipsoid with minimal trace of its matrix, ellipsoid containing given points, contained in the ellipsoid polyhedron, Deakin ellipsoid, ellipsoid maximum volume. The approach may be due to the a priori uncertainty of the data, or computational methods for solving timing and accuracy of decision-making or problem context.

Approximation of the feature points set is realized in systems of practical importance, so as geometric shapes to build models using circles, ellipses, and other objects, which can be determined by analytical equations. Note that approximation methods can be separated into geometric and algebraic [20,21]. 


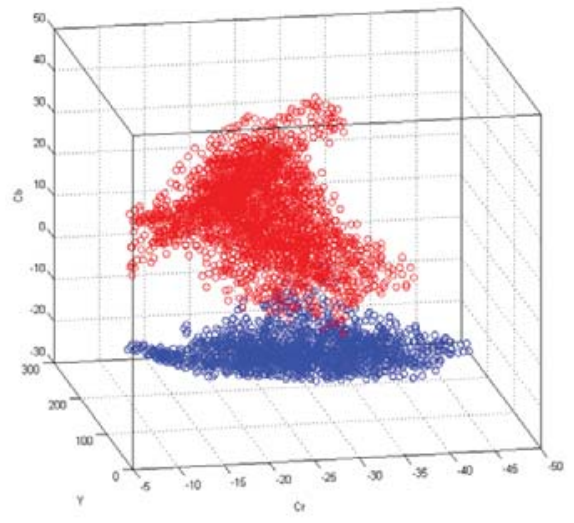

a)

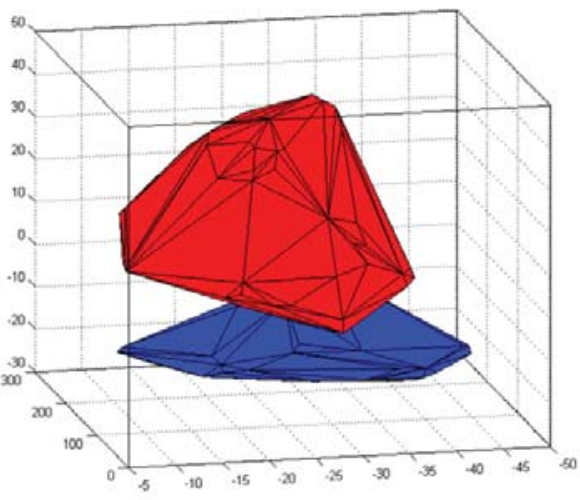

b)

Figure 4: Selective distribution of the $\mathrm{YCrCb}$ color space: $a-$ point presentation for scene, $b-$ model of the convex hull

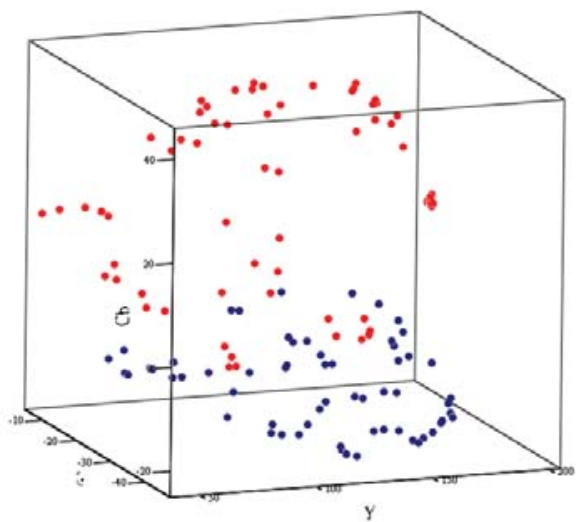

a)

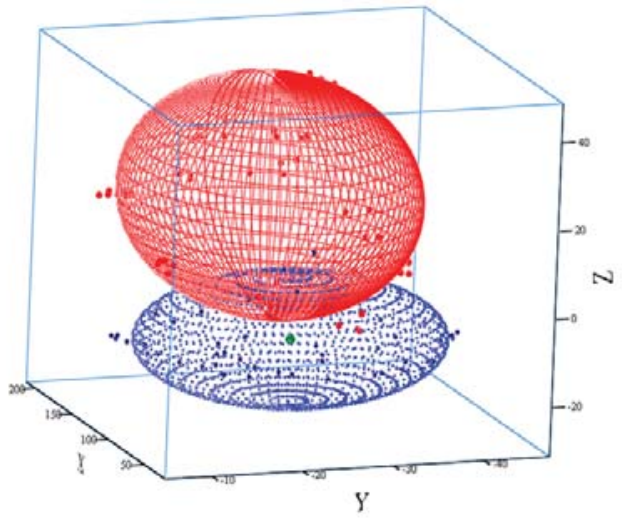

b)

Figure 5: Construction of the model for YCrCb color space: $a$ - points of the external shell (Figure $4, b), b$ - approximation of ellipsoids

Implementing geometric approach is a measure of the deviation between the point and the objective function when it is necessary to use a nonlinear optimization methods, which have to solve a computationally intensive task. An algebraic approach is applied to the square of the distance between points and admits an analytic solution of the optimization problem with minimal computational cost. Synthesis model sampling distributions approximating ellipsoid is expected to use a geometric approach.

So the potential to reduce computational costs, reduce the dimension of the points set which belong to the external convex hull. The result of such an operation can be visually observed in Figure 5 as well. In constructing the model must take into account the fact that the center of the ellipsoid must be approximated within the convex hull of the points, otherwise optimization problem it can lead to degenerate case. For example, a case where the entire set will be located near the surface of the ellipsoid.
Therefore, the Equation 4 must be reduced to the form:

$$
\frac{\left(x-x_{0}\right)^{2}}{a^{2}}+\frac{\left(y-y_{0}\right)^{2}}{b^{2}}+\frac{\left(z-z_{0}\right)^{2}}{c^{2}}=1
$$

where $x_{0}, y_{0}, z_{0}$ - center coordinates of the second order curve.

Using the method of least squares approximation to find the solution of this equation, which will minimize the sum of squared errors:

$$
\sum_{i=1}^{n}\left[f\left(x_{i}, y_{i}, z_{i}\right)\right]^{2} \rightarrow \min
$$

In this equation $x_{i}, y_{i}, z_{i}$ - approximated data, $x_{0}, y_{0}, z_{0}$, $a, b, c$ - approximation parameters to be evaluated, $f\left(x_{i}, \quad y_{i}, z_{i}\right) \quad$ - function approximation error. 
Options approximation results depend on the initial conditions, so as conditions approached asked - point of the gravity center for the set of initial points. Results approximation can visually assess in Figure $5 \mathrm{~b}$.

\section{ANALYSIS OF SEGMENTATION ALGORITHMS}

The models created using convex hulls and ellipsoid approximations made it possible to create a whole group of segmentation algorithms based on them. A group of algorithms based on a convex hull for different colorimetric spaces $A\left({ }^{*}\right)$ and segmentation based on ellipsoid approximations $B\left(^{*}\right)$. The results of evaluation of errors for the first $(F)$ and second kinds $(M)$ are given in Table 2 .

Table 2: Results of testing segmentation algorithms

\begin{tabular}{|c|c|c|c|c|c|}
\hline \multicolumn{3}{|c|}{ Convex hull model } & \multicolumn{3}{|c|}{$\begin{array}{c}\text { Approximation model } \\
\text { by ellipsoid }\end{array}$} \\
\hline & $\mathrm{F}$ & $\mathrm{M}$ & & $\mathrm{F}$ & $\mathrm{M}$ \\
\hline $\mathrm{A}(\mathrm{RGB})$ & 0,07 & 0,15 & $\mathrm{~B}(\mathrm{RGB})$ & 0,13 & 0,25 \\
\hline $\mathrm{A}(\mathrm{Lab})$ & 0,09 & 0,17 & $\mathrm{~B}(\mathrm{Lab})$ & 0,19 & 0,28 \\
\hline $\mathrm{A}(\mathrm{HSV})$ & 0,13 & 0,21 & $\mathrm{~B}(\mathrm{HSV})$ & 0,21 & 0,31 \\
\hline $\mathrm{A}(\mathrm{YCrCb})$ & 0,18 & 0,23 & $\mathrm{~B}(\mathrm{YCrCb})$ & 0,27 & 0,23 \\
\hline
\end{tabular}

So the analysis shows that for the group of algorithms using the model of convex hulls, the algorithm based on the RGB model has the minimal error of the first and second kind. In general, the algorithms of the group $A\left({ }^{*}\right)$ have a $60 \%$ less average error of the first kind and $70 \%$ less the average error of the second kind than the group of algorithms $B\left({ }^{*}\right)$.

\section{CONCLUSIONS}

The study deals with the theoretical approaches in the analysis and pattern recognition models for the formation of images on the key features. A statistical analysis of a given class image dynamically changing scenes with the assessment of the objects characteristics for inhomogeneous background. For sampling distributions background / object models derived convex hulls in different colorimetric spaces. Synthesized models of the spatial distributions, described by the equations of the second order. Synthesized models made it possible to create effective algorithms for segmentation of dynamically changing scenes with minimal classification errors.

This work supported by state order of the Ministry of Education and Science of the Russian Federation №2.3135.2017/4.6 and RFBR № 16-01-00451a.

\section{REFERENCES}

1. S. Belongie. C. Carson. H. Greenspan, et al. Color- and textnre-based image segmentation using EM and its application to content-based image retrieval. In Proceedings of the International Conference on Computer Vision (ICCV'98). Bombay. India. January 1998.

2. Sun Z., Bebis G., Miller R. On-Road Vehicle Detection: A Review // IEEE Transactions on pattern analysis and machine intelligence. May 2006. V. 28. N. 5. Pp. 694-711.

3. Biometricheskie metody zashhity informacii: uchebno-metodicheskoe posobie / A. M. Prudnik, G. A. Vlasova, Ja. V. Roshhupkin. - Minsk : BGUIR, 2014. - 123 p.

4. Strieker M. Similarity of Color Images / M. Strieker, M. Orengo Proceedings of the SPIE Conference. 1995. Vol.2420. Pp. 381-392.

5. Black. K Kaliol. G Fahmy, P Kuchi, S Panclianathan. Characterizing the high-level content of natural images using lexical basis functions. Human Vision and Electronic Imaging Conference SPIE 2003, Santa Clara.

6. Prjett U. Cifrovaja obrabotka izobrazhenij. Kn.1,2. M: Mir, 1982.

7. Oppengejm A., Shafer R. Cifrovaja obrabotka signalov. Izd. 2-e, ispr. - M.: Tehnosfera, 2007. - 856 p.

8. Ipatov Ju.A., Tockij A.A. Issledovanie izobrazhenij dinamicheski izmenjajushhihsja scen $v$ kolorimetricheskom prostranstve // Kibernetika i programmirovanie. - 2015. - № 4. - pp.36-48. DOI: 10.7256/2306-4196.2015.4.16158. URL: http://e-notabene.ru/kp/article_16158.html

9. Tochechnye polja i gruppovye obekty / Ja. A Furman, A. A Rozhencov, R. G. Hafizov, D. G. Hafizov, A. V. Kreveckij, R. V. Eruslanov; pod obshh. red. prof. Ja. A. Furmana. - M: FIZMATLIT, 2014. - 440 p.

10. Prikladnaja teorija sluchajnyh processov i polej / K. K. Vasil'ev, Ja. P. Dragan, V. A. Kazakov, V. R. Krasheninnikov, Ju. P. Kunchenko, V. A. Omel'chenko, A. P. Trifonov, A. A. Spektor ; pod red. K. K. Vasil'eva, V. A. Omel'chenko. - Ul'janovsk : UIGTU, 1995. - 256 p.

11. Ipatov Ju.A., Kreveckij A.V. Metody obnaruzhenija i prostranstvennoj lokalizacii grupp tochechnyh obektov // NB: Kibernetika i programmirovanie. - 2014. - № 6. - pp.17-25. DOI: 10.7256/23064196.2014.6.13642. URL: http://e-notabene.ru/kp/ article_13642.html

12. Kompleksnye i giperkompleksnye sistemy $\mathrm{v}$ zadachah obrabotki signalov /Pod red. Ja. A. Furmana. M.: Fizmatlit, 2004. 
13. Rjabinin K.B., Furman Ja.A., Krasil'nikov M.I. Provolochnaja model' prostranstvennogo gruppovogo tochechnogo obekta//Avtometrija, 2008, №3. - pp. 3-16.

14. Kreveckij A.V., Chesnokov S.E. Kodirovanie i raspoznavanie izobrazhenij mnozhestv tochechnyh ob\#ektov na osnove modelej fizicheskih polej// Avtometrija, 2002. - №3. - pp. 80-89.

15. Preparata F. Vychislitel'naja geometrija: Vvedenie / F. Preparata. M. Shepmos. - M.: Mir, 1989. - 478 p.

16. Bronshtejn E.M. Approksimacija vypuklyh mnozhestv mnogogrannikami// Sovremennaja matematika. Fundamental'nye napravlenija - 2007. - Tom. 22. pp. 5-37.

17. Kamenev G. K. Metod polijedral'noj approksimacii vypuklyh tel, optimal'nyj po porjadku chisla raschetov opornoj i distancionnoj funkcii// Doklad RAN. 2003.-388. - pp. 309-311.
18. Ovseevich A.I. Svojstva optimal'nyh jellipsoidov, priblizhajushhih oblasti dostizhimosti sistem s neopredelennostjami / A.I. Ovseevich, F.L. Chernous'ko // Izv. RAN «Teorija i sistemy upravlenija». - 2004.№ 4. - pp. 8-18.

19. http://cvxr.com/cvx/

20. Chernov N., Lesort C. Least squares fitting of circles // J. of Math. Imaging and Vision. 2005. Vol. 23. Pp. 239-251.

21. Mikhlyaev S.V. Method for measuring the diameter of a growing crystal // Pattern Recognition and Image Analysis. 2005. Vol. 15, №4. Pp. 690-693. 